\title{
Psicoterapia dinámica breve realizada en una unidad de agudos hospitalaria de salud mental. A propósito de un caso.
}

Brief dinamic psychotherapy conducted in the hospital unit for acute mental health patients. A case report.

\section{Luisa Gutiérrez López a}

${ }^{a}$ Residente de psiquiatría de cuarto año del Área Hospitalaria de Valme. Dos Hermanas (Sevilla).

Correspondencia: Ma Luisa Gutiérrez López (marisagulo@hotmail.com)

Recibido: 09/01/2011; aceptado con modificaciones: 03/05/2011

RESUMEN: Se expone una experiencia en psicoterapia dinámica breve realizada en un varón de 48 años, ingresado en una Unidad de Agudos Hospitalaria de Salud Mental. Modelo de psicoterapia breve dirigida a trabajar la afectividad del paciente, haciendo del sentimiento el foco terapéutico y de la adquisición de un mejor manejo de éstos, el objetivo principal. Con el propósito de obtener herramientas psicoterapéuticas útiles allí donde la limitación temporal es un hándicap fundamental.

PALABRAS CLAVE: Psicoterapia breve, afectividad, sentimientos.

\begin{abstract}
We describe a brief psychotherapy experience made on a 48 year old man admitted to the Hospital Units for Acute Mental Health Patients. This psychotherapeutical model is directed to work the patient's emotions, making his feelings the therapeutic focal point. The main objective of this brief psychotherapy was the acquisition of better management of the patient's emotions and feelings. We aim at gaining useful psychotherapeutic tools where time is a major handicap.

KEY WORDS: Brief psychotherapy, emotions, feelings.
\end{abstract}

"Es de creer que las pasiones dictaron los primeros gestos y que arrancaron las primeras voces... No se comenzó por razonar sino por sentir"

JEAN-JACQUES ROUSSEAU

\section{Introducción}

La psicoterapia breve es por lo menos tan antigua como los esfuerzos de Freud para hallar cura a la neurosis. Así como la psicoterapia moderna debe sus orígenes a la teoría psicoanalítica, también lo hace el concepto de psicoterapia breve (1). En 1937 Freud influido por Ferenczi y su "método activo", y Rank y la experiencia de la "policlínica psicoanalítica", se plantea él mismo la necesidad de abreviar el psicoanálisis (2).

Fueron Alexander y French en Chicago, quienes describieron las características básicas de las terapias breves intentando mantener los esquemas teóricos del psicoanálisis. En la década de los cincuenta en la Clínica Tavistock de Londres, 
Balint y Malan desarrollan los cimientos sólidos para la práctica clínica de la psicoterapia breve.

Relevantes han sido también las importantes aportaciones a finales de la década de los años sesenta y principios de los setenta, que desde una óptica sistémicorelacional, realiza la escuela de Palo Alto a través de la obra de Bateson, Weaklan, De Shazer y Watzlawick. Destacar además los trabajos realizados por Lindeman, Kardiner y Wolberg y Bellak y Small en Estados Unidos. Más actual, la obra de Sifneos en la Universidad de Havard, con la "psicoterapia de corta duración generadora de ansiedad" y Davanloo, en la Universidad de McGil, que amplía el concepto al de "intervención en crisis". Por último, la obra de Weissman y Klerman, psicoterapia de corta duración denominada psicoterapia interpersonal (3).

Se expone aquí un modelo de psicoterapia breve dirigida a trabajar la afectividad del paciente, haciendo del sentimiento el foco terapéutico, y de la identificación, expresión, regulación y transformación de éstos, el objetivo principal $(4,5)$. La importancia del papel que juegan los sentimientos en la etiopatogenia de la enfermedad psíquica es fundamental. Schneider aseguraba que los sentimientos son estados del yo, al igual que las pulsiones y las sensaciones. De los sentimientos corporales diferenciaba sentimientos anímicos o actos emocionales y dentro de ellos incluía diferentes modalidades. Por un lado, los sentimientos de estado; agradables como la alegría, serenidad, satisfacción, confianza.... o desagradables, como el temor, desamparo, desconcierto, desesperanza.... Por otro, refería sentimientos valorativos, estos últimos muy relacionados con la valoración propia; vergüenza, culpa, remordimiento.... o la valoración ajena; desconfianza, desprecio, hostilidad.... Relataba posteriormente como se relacionaba el enfermar psíquico con un incremento o acentuación de estos sentimientos (6).

Numerosos autores han hecho alusión al puesto primordial que la afectividad tiene en psicoterapia. Beck señalaba como la eficacia de la relación terapéutica dependía en gran medida de la capacidad del paciente para experimentar y expresar sus sentimientos (7). Según Bolwlby, sólo puede esperarse un cambio terapéutico cuando el paciente toma conciencia emocionalmente de qué y cómo está sintiendo, y cómo esto está modificando o influyendo en su manera de comportarse. Lo sentido es por tanto, para él, reflejo del modo en que se evalúan determinadas situaciones y del tipo de conducta que se activa en el interior del individuo (8).

Entendiendo la afectividad como el conjunto de emociones y sentimientos que el individuo experimenta en la relación con el medio externo y con su propio interior, al trabajar el afecto, la manera de sentir, se proporciona al sujeto un medio de control sobre el estado de su conducta. El paciente aprende que una modificación del significado que adjudica a sus experiencias produce en él una modificación de lo sentido, pudiendo comportarse entonces fácilmente de una manera más adaptada y rentable. 
NOTAS CLÍNICAS

\section{Caso clínico}

Se describe un caso de un varón de 48 años que acudió al Servicio de Urgencias del Hospital de Valme por ideación autolítica persistente y alucinaciones auditivas. En relación a los antecedentes psiquiátricos, había sido ingresado en Unidad de Agudos de Salud Mental en diversas ocasiones desde el año 2007, con orientación diagnóstica, en el último ingreso de episodio depresivo moderado (F32.1 CIE10). Estaba en tratamiento con risperidona $3 \mathrm{mg} / 24 \mathrm{~h}$, ac. valproico $1500 \mathrm{mg} / 24 \mathrm{~h}$, citalopram $20 \mathrm{mg} / 24 \mathrm{~h}$ y flunitrazepam $1 \mathrm{mg} / 24 \mathrm{~h}$.

En el momento del actual ingreso y desde hacía seis meses, en el contexto de duelo por el fallecimiento de su hija, relataba incremento de la ansiedad, tristeza, anhedonia, apatía, abandono de actividades, y alucinaciones auditivas en el espacio externo. Eran voces imperativas e insultantes que tenían en él importante repercusión conductual y afectiva: "Empezó como un rumor y ahora son claras, como si alguien me hablara... Se hacen más fuertes y no puedo controlarlas, me dicen que me haga daño, también me insultan...". Estaba consciente, orientado auto y alopsíquicamente, euproséxico. Su actitud era de colaboración y no presentaba alteraciones groseras en funciones superiores. El lenguaje era fluido, espontáneo y coherente. Refería sentimientos de culpa por la reciente muerte de su hija, desconfianza de todos aquellos que le rodeaban, y desamparo y soledad en relación a su situación vital. Tenía ideas de muerte y autolisis. Se quejaba de insomnio con despertares intermitentes y frecuentes pesadillas. Disponía de nulo soporte familiar y social y había abandonado progresivamente su trabajo.

\section{Datos biográficos}

\section{Niñez y adolescencia}

Siendo muy pequeño sus padres emigraron y él, que era el mayor de seis hermanos, se quedó en España, al cuidado de sus abuelos paternos. Recuerda una infancia feliz, protegido y arropado por ellos, a los que llegó a considerar como sus padres. Definía a su abuelo como buena persona, responsable y trabajador. A su abuela, "Una santa, volcada en mi y en todos...". Con ellos vivía su tía y un hijo de ésta, con el que compartió juegos y afecto. Paso la infancia y adolescencia separado de sus padres. A pesar de que estos regresaron del país al que emigraron, nunca consiguió integrarse en la familia nuclear. Sin entender el por qué, comentaba haber sentido en ocasiones culpa por ello. Describía a su madre como distante y egoísta; a su padre más afectuoso, pero ambos, "Incapaces de hacer nada por mí". Se crió con mayor nivel económico que sus hermanos, lo que despertó en éstos 
recelos y críticas constantes y en él, clara desconfianza en la relación. En el colegio e instituto fue ejemplar, tenía buenas notas y nunca tuvo problemas con sus compañeros y profesores. En aquella época, se describía a sí mismo como "Trabajador, guasón, amable y entregado a todos...". Cursó estudios superiores, ejerciendo posteriormente en su profesión con éxito durante años.

\section{Vida adulta}

Después de un noviazgo normalizado se casó y tuvo dos hijos: una niña y un niño, seis años menor. El matrimonio no fue bien, sentía que su esposa estaba aliada con su madre y sólo en escasas ocasiones podía imponer su criterio. Su hija, era para él, "La única en el mundo que me defendía y apoyaba ante las críticas".

El primer conflicto relevante surgió quince años atrás al morir sus abuelos. Por cuestiones en relación a la herencia, se sintió duramente criticado por sus padres y hermanos, lo llamarón entonces "Niño rico y aprovechado...". Dos o tres años después del episodio comentado, tuvo importantes problemas a nivel laboral; tema que generó en él un profundo malestar; comenzó a sentirse intensamente inseguro y desconfiado, reduciendo progresivamente su labor profesional. Se hizo entonces patente la conflictiva conyugal y tras la separación matrimonial, un año antes del ingreso, la hija mayor enfermó gravemente y falleció seis meses después. Ahora vivía sólo y mantenía relación con vecinos del barrio donde residía. Disfrutaba de pequeñas tertulias en los bares cercanos que fue abandonando por su irritabilidad creciente, facilitada por el consumo abusivo de alcohol.

\section{Psicoterapia breve}

Se propuso al paciente la realización de una psicoterapia dinámica breve durante su ingreso en la Unidad de Agudos. El número de sesiones no se concretó al inicio, quedando esto a expensas de la evolución y tiempo del ingreso. Se realizaron doce sesiones de cuarenta minutos de duración. Como criterios de inclusión se tuvieron en cuenta: la capacidad que presentaba el paciente para pensar sobre sus sentimientos, la existencia de varias relaciones significativas en el pasado y la buena capacidad de vinculación con el terapeuta. 
NOTAS CLÍNICAS

\section{Hipótesis Psicodinámica Inicial}

Los mecanismos adaptativos del yo desplegados desde la infancia como la constancia, capacidad de trabajo, responsabilidad, entrega a los demás y calidez afectiva proporcionaron al paciente una adecuada imagen del sí durante años. Ninguna de estas cualidades habían logrado mantenerse tras el duro golpe de la muerte de su hija (factor desencadenante). Debilitado a nivel emocional por el fracaso de la relación conyugal, a nivel profesional por el conflicto laboral y aislado socialmente por las consecuencias del consumo excesivo de alcohol, fue invadido por sentimientos reactivados desde el pasado, surgidos en etapas no resueltas del desarrollo infantil, cuando fue excluido de la familia nuclear (conflicto nuclear). Sentimientos de culpa, desconfianza, desamparo y soledad, que en el presente provocaron una importante quiebra de la imagen de sí, de los límites del yo y del sentido de la realidad. Vencido por la puesta en marcha de mecanismos defensivos como la introyección, interiorizando el objeto persecutorio, las voces y la identificación con el objeto idealizado, las figuras de la abuela e hija, deseando morir como ellas, se mostraba incapaz de enfrentar su propio sustento y destino.

\section{Trabajo en el Foco}

Teniendo en cuenta la hipótesis psicodinámica inicial, se seleccionaron los sentimientos de culpa, desconfianza, desamparo y soledad como foco terapéutico. Estos sentimientos se abordaron desde una perspectiva cognitiva, emocional y conductual, intentando facilitar al paciente su identificación, expresión, regulación y transformación:

Sentimiento de culpa: se sentía terriblemente culpable de la enfermedad y posterior fallecimiento de su hija. Se facilitó la expresión de este sentimiento, aumentando la conciencia de su presencia en el pasado. Se abordaron las fantasías de omnipotencia y creencias mágicas, la aceptación de los límites propios y el reconocimiento de los límites de la naturaleza humana. Para favorecer la reparación del daño y la transformación del sentimiento, se le animó a la conducta de ayuda y entrega a los demás pacientes, personas necesitadas como él.

Sentimiento de desconfianza: sentimiento que emergió tras la conflictiva familiar y laboral. Con la intención de trabajar la confianza en sí mismo, base de la posibilidad de confiar en los demás, se hizo un intento de reestructurar la imagen de sí y la autoestima perdida, ofreciéndole una experiencia emocional correctiva, en el contexto de la relación terapéutica, al valorarle y reforzar con frecuencia sus cualidades, entre ellas, su generosidad, entrega y capacidad de apego. Además se le instó a contactar con su tía y primo que residían ahora en otra ciudad, con los que había mantenido una relación de confianza y apego. 
Sentimiento de desamparo y soledad: La muerte de sus abuelos y su hija, el divorcio y el aislamiento social favorecieron ambos sentimientos. Se trabajó la resolución del duelo, facilitando la identificación y expresión de la rabia por la muerte de sus seres más queridos y señalando la permanencia de las relaciones de objeto en el interior. Además, se destacó la importancia de la ayuda recibida desde el exterior, de la institución sanitaria. Tomó en aquel momento conciencia del miedo a enfrentar su situación, a vivir en soledad y se le propuso entonces reiniciar el contacto telefónico con amigos y compañeros.

\section{Evolución}

Progresivamente su estado de ánimo mejoró, incorporándose a las actividades de la Unidad con motivación y entrega. Cedió la ideación autolítica y aunque permanecieron las alucinaciones auditivas, dejaron de provocarle angustia y miedo a la desintegración. Fue capaz de elaborar la pérdida de sus seres más queridos, se apaciguaron los sentimientos de culpa, desconfianza y desamparo. Mejoró su autoestima; se sintió más capaz y valioso y en su corazón creció la esperanza, la confianza y la necesidad de compartir. Inició conversaciones telefónicas con su primo y tía, que le hicieron sentir reconfortado. En el momento del alta había reanudado la relación con amigos y vecinos, además de tener proyectos laborales inminentes.

Respecto a la orientación diagnóstica, durante el ingreso se planteó el diagnóstico diferencial entre Trastorno depresivo grave con síntomas psicóticos (F32.3) y el Trastorno psicótico residual secundario al alcohol ((F10.5 CIE-10). La persistencia de las alucinaciones auditivas a pesar del tratamiento, inclinaron la balanza hacia el Trastorno psicótico residual. Fue dado de alta con risperidona 9 $\mathrm{mg} / 24 \mathrm{~h}$, venlafaxina retard $150 \mathrm{mg} / 24 \mathrm{~h}$, clometiazol $486 \mathrm{mg} / 24 \mathrm{~h}$ y flunitrazepam $1 \mathrm{mg} / 24 \mathrm{~h}$.

\section{Conclusiones}

Tres factores principales exigen la consideración de la unión de la combinación psicofarmacoterapia-psicoterapia en los pacientes ingresados en la Unidades de Agudos Hospitalarias; el primero, conseguir un incremento de la eficacia en la fase aguda, por otro lado, amplificar el alcance de la respuesta y por último, reducir el riesgo de recaídas (9). Por ello, se ha descrito un modelo de psicoterapia 


\section{NOTAS CLÍNICAS}

dinámica breve como propuesta ante la necesidad de adecuar la psicoterapia a los diferentes modelos institucionales, siendo posible que sea este tipo de psicoterapia la que mejor se adapte para su utilización a nivel hospitalario (10).

Parece que el abordaje precoz de la afectividad, trabajando sobre los sentimientos que el paciente muestra en primer plano, podría traducirse en una mayor eficacia en la intervención. Se comprobó en este caso, cómo estos sentimientos, gestados en el pasado y reactivados en el presente, provocaban un deterioro en la valoración del sí mismo que hacían poner en cuestión, al paciente, el sentido de la vida para el futuro. Sería importante demostrar que el trabajo sobre estos sentimientos y su significación, pudiera representar una forma de prevención, al actuar sobre el futuro. Una psicoterapia breve del "aquí y ahora", con nexos importantes en el pasado y pretendiendo un cambio de significación, al respecto del sentimiento y del sí mismo, que permita una modificación beneficiosa en el sentir para el futuro.

\section{BIBLIOGRAFÍA:}

(1) Small L. Psicoterapia Breve. $3^{\text {a }}$ ed. Barcelona: Gedisa; 1997.

(2) Freud S. Die endliche und unendliche analyse. En: Freud obras completas. Barcelona: Orbis; 1988, p. 3339-3364.

(3) Kaplan HI, Sadock BJ. Psicoterapia breve e intervención en crisis. En: Sinopsis de Psiquiatría. $8^{a}$ ed. Madrid: Panamericana Willians \& Wilkins; 1998, p. 852-856.

(4) Fiorini HJ. El concepto de foco. En: Teoría y Técnicas en Psicoterapia. $19^{\mathrm{a}}$ ed. Buenos Aires: Nueva Visión [seriada en línea] 2002, p 1-5 [consultado 26-12- 2010]. Disponible en: http: //www. hectorfiorini.com.ar.

(5) Geenberg LS. Terapia centrada en las emociones: una síntesis clínica. FOCUS. APA Lifelong Learning in Psych (Barc): Medical Trends, 2010; 1: 37-47.

(6) Schneider K. Klinische psychopatholgie. $4^{\text {a }}$ ed. Madrid: Paz Montalbo; 1975.

(7) Beck AJ, Rush AJ, Shaw BF, Emery G. Cognitive therapy of depression. 16 ed. Vizcaya: Desclee de Brouwer; 2005.

(8) Bowlby J. Evaluación y selección: sentimiento y emociones. En: Bowlby J. El Apego y la pérdida. Barcelona: Paidos; 1998, p. 157- 180.

(9) Kennedy SH, Lam RW, Nutt DJ, Thase ME. Treating depression effectively. $2^{\text {a }}$ ed. Andover: Informa Healthcare; 2007.

(10) García E., Zamarro M.L. Psicoterapia breve en instituciones públicas: a propósito de dos casos clínicos. Rev. Asoc. Esp. Neuropsiqui. Madrid: 1990; 10(32): 89-95. 